\title{
Study on Characteristics of Leakage Accident of Hazardous Chemicals and Their Rescue
}

\author{
Quanmin Bu, Weining Cai, and Xing Tong
}

\begin{abstract}
Leakage accident of hazardous chemicals is a urgent task for fire forces in emergency rescue. Analysis on characteristic and law of leakage accident and finding out its impact on emergency rescue is a pressing matter, they have important significance in both theory and practice.
\end{abstract}

Index Terms-Hazardous chemicals, leakage, emergency rescue.

\section{INTRODUCTION}

Leakage accident of hazardous chemicals refers to leakage of dangerous chemicals in their production, transport, storage and use, due to design defects, illegal operation, equipment failure and other reasons, it may cause environmental pollution, fire and explosion, casualties and other serious consequences.

At present, with the rapid development of petroleum and chemical industry, a huge number of dangerous chemicals are in production line or stored in warehouses of chemical enterprises, a large amounts of chlorine, ammonia, hydrogen fluoride, formaldehyde and other dangerous chemicals are used and discharged in chemical production process, or transported with tank car or delivery pipe. [1] Apart from that, war, vandalism, natural disasters and other factors also cause potential threat for their leakage accidents.

\section{GoOd Understanding OF HAZARDOUS CHEMICALS' Characteristics, Namely Toxic, Flammable, EXPLOSIVE}

Many chemical materials have characteristics of strong poison. For example, gas, sulfur dioxide, ammonia, benzene and homologues are toxic substances, phosgene, prussic acid, formaldehyde, hydrogen fluoride, chlorine, nitrogen dioxide are highly toxic substances, their maximum allowable concentrations are below 300ppm in the air. [2] Phosgene

\footnotetext{
Manuscript received December 16, 2012; revised March 12, 2013. This work was supported in part by Jiangsu science and technology support program (BE2010738); Jiangsu colleges and universities natural science foundation funded project(08KJB620001); Qing Lan Project, "333” Project and PAPD.

Quanmin $\mathrm{Bu}$ is with the Public Security and Management Department, Jiangsu Police Institute and the Center for Social Risk and Public Crisis Management of Nanjing University, Nanjing, China (e-mail: u0857366@umail.utah.edu).

Weining Cai is with the Investigation Department, Jiangsu Police Institute, Nanjing, China (e-mail: caiweining@@jspi.edu.cn).

Xing Tong is with the Center for Social Risk and Public Crisis Management of Nanjing University, Nanjing, China (e-mail: qmbu@sina.com).
}

and prussic acid are regarded as standard military toxicants in many nations, their toxicity is quite strong, human and animals will be poisoned or even die in the air with high concentration of the toxicants. [3] And most of chemical industrial toxicants have low boiling point, low lighting point, low flash point, as well as flammable and explosive characteristic. [4] For example, benzene, toluene, methylbenzene, prussic acid and methanol's flash points are below $28^{\circ} \mathrm{C}$; Gas, liquefied petroleum gas, formaldehyde and acetylene's lower explosion limit is below $10 \%$, they are belong to the first-class hazardous substance. Thus, in leakage accident of chemical toxicants, there are fire, explosion and combustion. In order to deal with such dangerous environment in emergency rescue, the following six problems must be solved:

1)A strong rescue team must be available;

2)Their quality and expertise's must be excellent. They must be brave when facing danger, they must also have a good master of relevant theories and be able to protect themselves, and deal with all kinds of toxicants;

3)All relevant equipments must be available. Personal protective equipments (gas mask, fully enclosed protective clothes and fire-retardant suits) and rescue equipments (dangerous chemicals and rescue vehicles, deter exhaust equipment, laboratory equipment) should be available;

4)Command should proper. Command agencies at all levels should give order timely and correctly;

5)Action should be proper. Namely, after arriving at the scene, reconnaissance, surveillance, wave attack must be conducted in order;

6)Security should be sufficient. Because of toxic, flammable, explosive characteristics of chemical leakage accidents, rescue personnel's living benefits and personal insurance should be enough.

\section{Characteristics OF LEAKAgE ACCIDENTS OF HAZARDOUS CHEMICALS}

"Leakage" is the leading cause of dangerous chemicals accidents; the reasons for the leakage may be operation error, equipment malfunction or aging, design deficiency, etc. According to investigation on many years of statistics about chemical accidents, leakage usually occurs in pressure vessel, valve and old pipe' which is proved by several major domestic accidents. For example, the explosion accident of large-scale liquefied gas tank in Xi'an city is due to rupture of valve. [5] In rescue process, plugging is crucial, there are mainly two ways. 


\section{A. Rapidly Close Valves Which are Related to Leakage} Points to Avoid Further Leakage of Chemicals; This is the Fastest and Most Effective Plugging Way

In order to carry out this method, daily preparation is quite critical. This requires rescuer to conduct serious and meticulous investigation on all possible leakage points before accident, so as to set realistic emergency rescue plan, otherwise field investigation is too late when a accident occurs. [6] At the same time, with shrouded poisonous gas and chaos in the scene, rescue workers may not find out the cause without the help of technical personnel.

\section{B. Use Special Tools and Equipments for Plugging}

They mainly refers special tools which realize temporary and fast plugging through pressing, fixing and adhering, such as domestic injection remover, metal magnetic sucker and imported pressure plugging bags, in addition to flange and pipeline cork and clip. Research and trial production of the special tools should be completed by rescue team and corresponding enterprises under the leadership of rural rescue headquarter. [7] Without these special tools and equipments, it is difficult to complete rescue task when a special leakage accident occur. Take the explosion accident of large-scale liquefied petroleum gas tank in Xi'an city for example, because of lack of special tools, low ignition point and lower explosion limit, explosion happened.

\section{Characteristics of Leakage ACCidents of HAZARDOUS CHEMICALS-SUDDENNESS, QUICK AEROSOL MASS DIFFUSION}

Because people pay universal attention to safety of chemical production, many regulations have been in place, and people master certain law for occurrence of leakage accidents. However, because there are many triggering factors, leakage accidents often happen unexpectedly. First of all, accident site is uncertain, for example: in the progress of being transported, the accidents may happy anywhere. Secondly, the time of accident is also uncertain.

\section{Diffusion of Toxic Cloud is AfFected By WeAther AND TERRAIN CONDITIONS}

\section{A. Diffusion of Toxic Cloud is Affected by Weather and Terrain Conditions}

Meteorological conditions that affect diffusion of toxic cloud are wind, precipitation, temperature, atmosphere stabilization, etc. [8] According to repeated experiments by Chinese chemical defense army, their effects are as follows:

1)Effect of wind: wind direction, stability of wind direction and wind speed. The three factors determine geographical range and concentration of diffusion. Wind direction determines diffusion direction of toxic cloud, wind stability determine its diffusion width. In the absence of prominent terrain conditions, toxic clouds diffuse as wind direction. High wind speed will lead to high diffusion speed, large diffusion distance and diffusion area, but concentration is low. If wind speed is too high, most areas' concentration will be below allowable concentration level, hazardous area will also narrow. When there is no wind, toxic cloud diffuse around, the concentration of toxic materials in leakage ares will be very high, and increase poisoning degree.

2)Effect of precipitation: precipitation includes rain and snow. Heavy rain will reduce concentration of toxic cloud to some degree; some toxic materials dissolve in rainwater. For example, ammonia dissolves in soluble and become ammonia water. But light rain and snow have little impact on concentration of toxic materials.

\section{B. Analysis of Thermal Explosion}

Thermal explosion of organic flammable and explosive substances refers to the automatic and uncontrollable explosion happening under the effect of heat. Its theory mainly involves the study of the possibilities of and critical conditions for (such as geometrical size and temperature) thermal explosion as well as the study of the dynamics problems of thermal explosion when the critical conditions are satisfied.

The basis of the research of thermal explosion is the research of the relations of exothermicity, velocity, and temperature. When the exothermic heat from the reaction carried out at a fixed rate and temperature does not radiate in time, the temperature of the reaction system will increase; with the increase in temperature, the velocity also increases, and thus the temperature will increase more. But it is possible that the heat will transfer to the surroundings and radiate, so due to the difference between exothermic controlling system and radioactive controlling system, the reaction system may have the three situations as follows:

1) Exothermic velocity is smaller than radioactive velocity. In this situation, the heat radiates quickly and the temperature drops, so there is no automatic increase in the temperature of the reaction system and thermal explosion will not occur.

2) Exothermic velocity is bigger than radioactive velocity. In this case, the temperature increases gradually since the heat cannot radiate in time. With the increase in temperature, the reaction velocity and exothermic velocity increase, too. Therefore, the temperature will increase all the time until the accident of thermal explosion happens.

3) Exothermic velocity is equal to radioactive velocity. Under the circumstances, exothermic heat and radioactive heat are in a dynamic balance, which can be called the critical point. The balance, because of any change of the conditions, can be broken and changes into: either (1) or (2). Thus the critical point is not only an important dynamic balance, but also a dangerous state.

\section{Toxic Cloud is also Susceptible to Topographical Conditions}

The topographical conditions which affect toxic cloud include terrain hilly land and settlement place; Mountain and hilly terrain are undulating, meteorological conditions there are more various, their effects on toxic clouds are also complex. [9] As for a independent hill, toxic cloud generally pass from its two sides, its top is not affected, it is better to evacuate the public towards the top of the hill. As for mountains, toxic cloud may flow around, the concentration of materials in some areas may increase, but overall, toxic air diffuse more quickly, diffusion range greatly reduce. 
Effect of settlement place: The effect of settle place on toxic cloud is also very complicated, shape, direction, width of streets, height and size of buildings all has impact on wind direction and wind speed to different degree. When toxic cloud pass through settlement place, some of them pass through, some of them remain there. When there is convection current, the cloud rise, when there is .temperature inversion, it is safe to stay within the buildings, since the cloud flow into underground building, and diffuse through underground paths or pipes. When there is wind, the street' direction has a critical on diffuse direction. If the street is wide and it has the same direction as wind, or the intersection angle is not greater than $30^{\circ}$, or wind speed is $\left.4 \sim 8\right) \mathrm{m} / \mathrm{s}$, the cloud will pass through smoothly; If the intersection angle is $30^{\circ} \sim 60^{\circ}$, the cloud move more slowly; If the intersection angle is $60^{\circ} \sim 90^{\circ}$, and buildings are not high, the cloud can pass through, if buildings are high, it may be stopped; The cloud may also sty in blind alley, by-lane, courtyard and the leeward area. In a word, larger wind speed and lower buildings allow the cloud to flow more quickly.

Since toxic cloud is susceptible to weather, topography characteristics, it is necessary to consider the follows in emergency rescue:

1)All personnel in headquarter and rescue team should strengthen their meteorological knowledge, and understanding characteristics of weather's effect;

2)119 command center should regard the collection of weather data as important working content;

3)It is necessary to carry out detailed meteorological reconnaissance on areas around the source of disaster, especially for a mountainous city, so as to offer accurate data for a computer decision system.

\section{REFERENCES}

[1] W. L. Duan, G. H. Chen, Q. Ye, and Q. G. Chen, "The situation of hazardous chemical accidents in China between 2000 and 2006," Journal of Hazardous Materials., vol. 10, no. 2-3, pp. 1489-1494, June 2011.

[2] F. Rigas and S. Sklavounos, "Major Hazards Analysis for Populations Adjacent to Chemical Storage Facilities," Process Safety and Environmental Protection., vol. 10, no. 5, pp. 341-351, May 2004.

[3] C. Samuel, N. Keren, M. C. Shelley, and S. A. Freeman, "Frequency analysis of hazardous material transportation incidents as a function of distance from origin to incident location," Journal of Loss Prevention in the Process Industries., vol. 22, no. 6, pp. 783-790, June 2009.
[4] V. Kazantzi, N. Kazantzis, and V. C. Gerogiannis, "Risk informed optimization of a hazardous material multi-periodic transportation model," Journal of Loss Prevention in the Process Industries., vol. 24, no. 6, pp. June 2011.

[5] A. Lozano, Á. Muñoz, L. Macías, and J. P. Antún, "Hazardous materials transportation in Mexico City: Chlorine and gasoline cases," Transportation Research Part C: Emerging Technologies., vol. 19, no. 5, pp. 779-789, May 2011.

[6] C. Winder, R. Azzi, and D. Wagner, "The development of the globally harmonized system (GHS)of classification and labelling of hazardous chemicals," Journal of Hazardous Materials., vol. 125, no. 1-3, pp. 29-44, May 2005.

[7] R. F. Tang, Y. Q. Bai, and T. Wang, "Research on GIS Application System of Environmental Risk for Hazardous Chemicals Enterprises," Procedia Environmental Sciences., vol. 10, no. 2, pp. 1011-1016, February2011.

[8] M. Verma, "A cost and expected consequence approach to planning and managing railroad transportation of hazardous materials," Transportation Research Part D: Transport and Environment., vol. 14, no. 5, pp. 300-308, October 2009.

[9] A. T. Gumus, "Evaluation of hazardous waste transportation firms by using a two step fuzzy-AHP and TOPSIS methodology," Expert Systems with Applications., vol. 36, no. 2, pp. 4067-4074, April 2009.

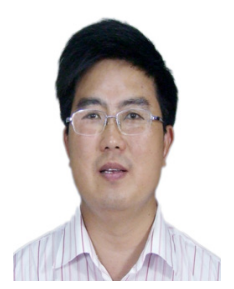

Quanmin Bu is an associate professor, an academic leader of Innovation Project of Jiangsu Province, a security expert for Jiangsu Provincial Public Security Department. His focus areas include safety analysis, evaluation and management of dangerous chemicals.

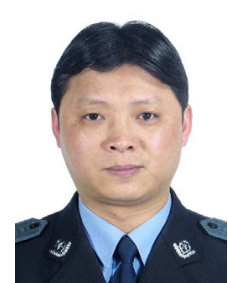

Weining Cai is an associate professor. Focus areas include safety analysis, evaluation, investigation and management of dangerous chemicals.

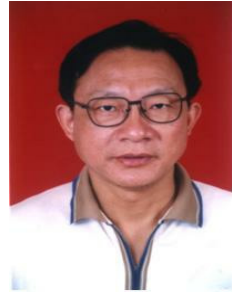

Xing Tong is a professor, a member of subject review group for national philosophy and social science planning fund, a member of National Disaster Reduction Committee, a member of National Postdoctoral Management Committee, a standing director of Jiangsu Philosophy Social Science Federation and a vice president of Jiangsu Development Research Institute. His focus areas include safety analysis, evaluation and management. 